\title{
AFINAL, 0 QUE É UMA MULHER? SIMONE DE BEAUVOIR E "A QUESTÃO DO SUJEITO" NA TEORIA CRÍTICA FEMINISTA
}

Ingrid Cyfer*

A recepção de $O$ segundo sexo de Simone de Beauvoir foi e ainda é bastante controversa. Apesar disso, Beauvoir declarou que, de todos os seus livros, O segundo sexo foi o que lhe trouxe maiores satisfações e que jamais deixou de corroborar as ideias fundamentais dessa obra (Beauvoir, 2009 [1963], p. 217). Essas ideias, como se sabe, constituíram um dos principais marcos teóricos do feminismo, mas, se comparado a seu auge nas décadas de 1960 e 1970, pode-se dizer que perdeu espaço no debate teórico.

Na França, o declínio da importância de Beauvoir para a teoria feminista costuma ser atribuído à ascensão do pós-estruturalismo e à influência que essa corrente teve no feminismo. Nesse contexto, a maior parte da produção acadêmica sobre Beauvoir migra para os Estados Unidos, a ponto de, como observa Toril Moi (1990, p. 25), na década de 1980, dez dos treze livros sobre Beauvoir terem sido publicados naquele país. No entanto, foi somente após a sua morte, em

* Agradeço à Fundação de Amparo à Pesquisa do Estado de São Paulo (Fapesp) pela concessão da Bolsa de Pesquisa no Exterior (BPE) que financiou a pesquisa da qual resultou este artigo. 
1986, e a publicação de seus escritos privados, que a contribuição filosófica de Beauvoir seria realmente reconhecida mesmo nos Estados Unidos. Esse "renascimento dos estudos de Beauvoir", porém, será muito rapidamente ofuscado pelo forte apelo que o pós-estruturalismo francês passaria a exercer na reflexão feminista norte-americana na década de 1990, em particular após a publicação de Problemas de gênero, de Judith Butler (2003 [1990]).

O livro de Butler tornou-se uma referência teórica central para o feminismo em todo o mundo, tendo gerado muitos debates, dos quais um dos mais importantes, do ponto de vista da teoria política, corresponde à discussão entre Butler e Seyla Benhabib. As autoras divergem fundamentalmente em relação à concepção de sujeito e suas implicações na ação política. Benhabib identifica-se com a vertente da teoria crítica, para a qual é possível e necessário manter a teoria comprometida com uma concepção normativa 42 de igualdade; enquanto Butler equipara discursos igualitários a discursos de poder, mesmo quando são formulados e mobilizados por movimentos sociais como o feminismo.

Nessa discussão, Judith Butler levanta importantes questões teóricas e políticas que a teoria feminista passou a enfrentar de modo mais contundente. No entanto, o modo como Butler sustenta teoricamente sua crítica ao sujeito abstrato compromete a ideia de ação política capaz de transformar ou mesmo ultrapassar assimetrias sociais. Por isso, nesse embate, Benhabib parece estar correta em assinalar que, para criticar a essencialização do sujeito do feminismo e sua ilusória universalidade, não é necessário (nem tampouco desejável) abdicar da justificação de concepções de igualdade de gênero normativas ${ }^{1}$.

\footnotetext{
1 Discuto essa questão em minha tese de doutorado A tensão entre o feminismo moderno e pós-moderno na crítica à exclusão no feminismo (FFLCH-USP, 2009) e no texto que apresentei na Critical Theory Roundtable, de 2014, em Dartmouth College, "The tension between inclusion and exclusion in Judith Butler's work"; disponível em
} 
É na tentativa de defender essa ideia que Benhabib irá formular sua própria concepção de sujeito, o self narrativo, com a qual procura explicitar o modo como concilia a contextualização do sujeito e sua capacidade de transformar o contexto. No entanto, conforme salienta Amy Allen (2007, pp. 169-70), Benhabib não é completamente bem-sucedida nessa tarefa porque propõe uma concepção de núcleo do self neutro em relação ao gênero. Esse, por assim dizer, déficit de contextualização parece estar relacionado ao fato de Benhabib não ter explorado a relação entre corpo e subjetividade com a profundidade necessária para sustentar que, assim como não há um núcleo do self anterior ao contexto histórico, tampouco há um núcleo do selfsem gênero.

O principal argumento deste artigo é o de que o conceito de mulher que Beauvoir propõe em $O$ segundo sexo oferece a relação entre corpo e subjetividade que falta a Benhabib, complementando sua concepção de subjetividade de modo a dar conta dos projetos teóricos e políticos que motivam a reflexão de Benhabib sobre o sujeito do feminismo. Em outras palavras, o objetivo é integrar a reflexão sobre a subjetividade da mulher em Beauvoir ao programa de Benhabib de encontrar respostas para duas questões fundamentais: (1) como é possível contextualizar o sujeito sem reduzi-lo a mero efeito do contexto, desprovido de intencionalidade? e (2) como conciliar a crítica ao sujeito universal sem comprometer a possibilidade de justificar princípios morais e políticos igualitários? (Benhabib, 1999, p. 338).

Nas duas primeiras seções do artigo, apresento brevemente o debate teórico sobre a articulação entre subjetividade e ação política em Butler e Benhabib, para então apontar a contribuição de Beauvoir nessa discussão.

<https://www.academia.edu/9560431/The_tension_between_inclusion_and_exclusion_in_Judith_Butlers_work> (último acesso em: 13 fev. 2015). 


\section{O sujeito em Judith Butler}

O principal problema teórico do livro Problemas de gênero é o conceito de "mulher" na teoria e no movimento feministas. Butler afirma que o feminismo problematizou pouco esse conceito, pressupondo-o como uma categoria universal capaz de representar os interesses de todas as mulheres. Em sua visão, a presunção de universalidade e convergência dos interesses das mulheres, embora tenha cumprido um papel importante na promoção de sua visibilidade política, oculta as disputas e assimetrias entre as próprias mulheres (Butler, 2003 [1990], pp. 17-18).

O problema que está em jogo na discussão do sujeito do feminismo em Butler, portanto, é a legitimação e ocultação da exclusão que sua representação determina. Por isso, ela afirma que o sujeito é um problema central para a política feminista.

O sujeito é uma questão crucial para a política, e particularmente para a política feminista, pois os sujeitos são invariavelmente produzidos por via de práticas de exclusão que "aparecem", uma vez estabelecida a estrutura jurídica da política. Em outras palavras, a construção política do sujeito procede vinculada a certos objetivos de legitimação e exclusão, e essas operações políticas são efetivamente ocultas e naturalizadas por uma análise política que toma as estruturas jurídicas como seu fundamento. O poder jurídico "produz" inevitavelmente o que alega meramente representar; consequentemente, a política tem de se preocupar com essa função dual do poder: política e produtiva (Butler, 2003, p. 19).

Em Butler, portanto, as práticas de exclusão são constitutivas do processo de produção do sujeito. Esse processo, por sua vez, é ocultado e internalizado à medida que os sistemas de poder que o produzem alegam meramente representá-lo. É com base nessa relação entre poder e sujeito 
que Butler denuncia as exclusões engendradas pelo sujeito universal, mesmo em movimentos que reivindicam para si o papel de críticos do sistema de poder vigente, como o feminismo. Seu principal argumento, portanto, é o de que o sujeito que representa as demandas das mulheres é também um produto das relações de poder que pretende combater (Butler, 2007 [1990], p. 18).

Seguindo Foucault, Butler (2003, p. 18) sustenta que as noções jurídicas de poder que definem proibições, o incorreto e a exclusão não regulam a vida política apenas em termos negativos. Elas também produzem o padrão correto, os critérios de inclusão e inteligibilidade. Assim, os sujeitos não são apenas oprimidos ou regulados por essas normas, eles são também seu produto.

Nessa perspectiva, a crítica feminista às relações de poder opressoras vê-se, portanto, enredada em um paradoxo, uma vez que a "mulher universal" representada pelo feminismo é produto das mesmas relações de poder que pretende combater. Por isso, o feminismo deve, segundo Butler, evitar a estratégia política de buscar a causa abrangente da dominação da mulher, bem como a de definir o sujeito universal subordinado a essa dominação, pois desse modo legitima domínios de exclusão dentro do próprio feminismo (Butler, 2003, p. 19).

Em substituição a essa estratégia, Butler propõe como tarefa primordial do feminismo trazer à tona o processo de produção da "mulher universal" pelas estruturas de poder, revelando as exclusões que delas decorrem e que são por elas encobertas. Isso é o que Butler (2003, pp. 21-23) denomina "genealogia feminista" da categoria das mulheres.

Em Problemas de gênero, portanto, Butler (2007, p. 9) não está engajada em encontrar "uma identidade sexual genuína ou autêntica que a repressão impede de ver"². Ao

2 Todas as traduções de citações foram feitas pela autora para este artigo. 
contrário, seu objetivo é investigar as práticas, discursos e instituições que geram identidades, mas que designam estas últimas como sua causa e origem. A tarefa da genealogia feminista consistirá, em suma, em desvelar o processo de produção das identidades de gênero, alternando o centramento e o descentramento nas normas que as constituem, uma vez que é essa alternância que abala sua normalização e as exclusões que delas decorrem.

A principal norma na produção das identidades de gênero em Butler é a obrigatoriedade da heterossexualidade ou, nos termos dela, a heteronormatividade. A heterossexualidade não é, porém, uma forma de viver a sexualidade circunscrita à intimidade. Ela deve ser atestada publicamente pelo enquadramento em padrões comportamentais que aludem à heterossexualidade. Assim, ser reconhecido socialmente como homem ou mulher será uma condição alcançada pela manifestação pública de comportamentos 46 associados à masculinidade e à feminilidade. É por isso que Butler afirma que o gênero é performativo, ou seja, produzido por modos de agir identificáveis como masculinos e femininos. Assim, a alegada existência de uma essência feminina ou masculina seria um produto dessa performance, e não o contrário. É a repetição reiterada desses comportamentos que criaria a ilusão de que sua origem está em uma essência natural que precede e transcende a vida social, ou seja, as identidades de gênero são produzidas pelas regras de feminilidade e masculinidade que o comportamento de homens e mulheres supostamente apenas representa (Butler, 1993, p. 12).

A concepção de gênero performativo de Butler remete a uma concepção de crítica também performativa. Se não há um espaço fora do poder, a crítica às identidades de gênero será também produzida nesse contexto. No entanto, a performance crítica será aquela que, em vez de confirmar as regras de feminilidade e masculinidade, as irá proble- 
matizar (trouble), ou seja, são performances que desestabilizam a coerência entre comportamento, orientação sexual e identidade de gênero. Esse é o movimento de centrar-se e descentrar-se nas normas, a que Butler se refere quando define a genealogia feminista.

A possibilidade dessa dinâmica que traz à tona a instabilidade das definições está sempre presente porque a performance integra um modelo linguístico de ação, segundo o qual a repetição e a inovação, a necessidade e a contingência são articuladas na possibilidade de "ressignificação". O exemplo que menciona para ilustrar a crítica como performance é o da drag queen. A drag perturba a coerência do sujeito "mulher" ou "homem" porque confunde comportamentos associados ao masculino e ao feminino em uma mesma performance. Quando um corpo biologicamente identificado como masculino cumpre as normas sociais da feminilidade, a expectativa de coerência entre a dimensão prescritiva da identidade de gênero e sua realização é frustrada. Essa é uma performance que abala a certeza de que a feminilidade é um atributo natural de corpos anatomicamente femininos (Butler, 2003, p. 195). Essa desestabilização é a ressignificação dos padrões de masculinidade e feminilidade que a drag queen expressa com sua performance. Ou seja, a drag atua de modo a conferir ao feminino e ao masculino um significado divergente dos padrões de gênero hegemônicos, mas esse novo significado não é produzido por uma crítica externa de um agente dotado da intenção de questioná-los, mas sim por uma crítica que se apropria dos estereótipos de gênero em um contexto em que seu significado original é subvertido (Butler, 2007, p. xxiv).

A ressignificação, em síntese, põe em dúvida aquilo que é normalmente assumido automaticamente como real, como natural. Essa problematização não é em si mesma uma revolução política, mas, como diz a autora, "nenhuma 
revolução política é possível sem uma mudança radical em nossa noção sobre o que é possível e o que é real" (Butler, 2007, p. xxiv).

No entanto, para algumas importantes interlocutoras de Butler, sua concepção de sujeito implica uma concepção de crítica tão modesta que não é possível nem ao menos sonhar com uma revolução política que emancipe as mulheres de sua opressão. Na leitura de Seyla Benhabib, com o objetivo de situar o sujeito do feminismo, Butler o teria privado de seu potencial emancipatório. Isso porque, ao assumir como necessária a relação entre normatividade $\mathrm{e}$ exclusão, Butler teria sido obrigada a reduzir a crítica feminista à mera descrição das condições de validade da ação e do conhecimento em determinados contextos, comprometendo sua função de justificá-las (Benhabib, 1992, pp. 21617). O ponto central de Benhabib, portanto, é o de que as investigações sobre validade supõem critérios normativos 48 que, para Butler, nada mais são do que discursos de poder, e, sem um critério normativo, não seria possível qualificar a discriminação de gênero, ou as exclusões dentro do próprio feminismo, como algo a ser combatido.

Nesse mesmo sentido, Nancy Fraser afirma que, em Butler, a concepção de espaço social necessariamente assimétrico, que herda de Foucault, funciona em seu argumento para desqualificar a dimensão normativa da teoria feminista como mais um discurso de poder. Mas, segundo Fraser, a rejeição de Butler a concepções normativas de igualdade encobre uma concepção de inclusão intuitiva que não é teoricamente justificada nem tampouco discutida.

Estou absolutamente convencida de que o que quer que Butler diga que está fazendo em Problemas de gênero ou em qualquer outro lugar, seu trabalho é absolutamente saturado por todos os tipos de demandas normativas. Ela, como Foucault, resistiu à ideia de explicar o que aquelas 
demandas são e de refletir sobre a perspectiva normativa que está por trás delas, rejeitando a ideia que deveria justificar essa perspectiva. Isso parece problemático para mim. Penso que uma crítica responsável requer, em algum ponto, que você explicite a base normativa de sua crítica e tente defendê-la de uma perspectiva normativa justificada, dado o fato de que você não pode assumir que isso seja compartilhado por todos (Fraser, 2011, p. 205).

Seyla Benhabib e Nancy Fraser apontam, portanto, para as implicações da crítica ao sujeito do feminismo em Judith Butler e a própria possibilidade de o movimento vislumbrar e lutar por uma concepção de igualdade de gênero. No espaço social assimétrico em que os sujeitos são produzidos, não há lugar para qualquer concepção de igualdade normativa que justifique critérios que identifiquem as desigualdades a serem contestadas pelo feminismo. No entanto, Fraser e Benhabib tampouco consideram o recuo ao sujeito pré-social mais promissor para a crítica feminista pelas razões que Butler muito bem diagnosticou em Problemas de gênero. Assim, o dilema teórico que o sujeito em Butler apresenta é o de situar o sujeito em seu contexto, sem com isso invalidar a ideia de que a crítica ao contexto requer uma concepção de igualdade normativa. A fim de encontrar uma saída para esse dilema, Benhabib formula sua própria concepção de sujeito: o self narrativo ${ }^{3}$.

\footnotetext{
3 Nancy Fraser enfrenta esse mesmo dilema, mas o faz de modo distinto. Em vez de formular outra concepção de sujeito, Fraser incorpora o sujeito de Butler, produzido por relações de poder, pois, em sua visão, Butler oferece ferramentas teóricas para a realização do diagnóstico da desigualdade que faltariam a Benhabib. No entanto, Fraser afirma também que Butler não teria avançado na reflexão sobre concepções de igualdade de gênero porque teria se recusado a justificar a normatividade implícita em sua crítica à exclusão. Por isso, Fraser considera que entre Butler e Benhabib há uma falsa antítese. O projeto de Nancy Fraser de combinar o diagnóstico da desigualdade de Butler com o prognóstico da igualdade de Benhabib foi objeto de minha tese de doutorado, defendida em 2009 (ver nota de rodapé 1 deste artigo). Nesse trabalho, minha conclusão foi a de que não é possível introduzir uma
} 


\section{Seyla Benhabib: o self narrativo}

De acordo com Seyla Benhabib, uma das principais tarefas da teoria feminista contemporânea é encontrar respostas para a seguinte pergunta: como podemos ser constituídos por discursos sem sermos determinados por eles?

A resposta de Benhabib já está sugerida em seus textos mais antigos, como em Critique, norm and utopia (de 1986), em Situating the self (de 1992) e em The reluctant modernism of Hannah Arendt (de 1996). No entanto, a elaboração de um concepção de subjetividade só foi explicitamente articulada depois e a partir de seu debate com Judith Butler em um artigo intitulado "Sexual difference and collective identities: the new global constellation" (Benhabib, 1999).

O debate com Judith Butler é uma etapa importante da formulação do conceito de self narrativo ${ }^{4}$ de Benhabib, porque Butler é quem tematiza a relação entre sujeito do feminismo e ação política, explicitando o problema da 50 exclusão inerente à universalização do sujeito. Além disso, a radicalidade da crítica de Butler ao sujeito introduz na agenda da teoria feminista reflexões sobre o risco de se colocar em xeque a própria possibilidade de ação política. Assim, foi sobretudo tentando encontrar respostas para as provocações teóricas e políticas em Problemas de gênero, que

\footnotetext{
concepção de igualdade normativa no diagnóstico de Butler. Isso se dá porque tal diagnóstico está assentado no modo como ela concebe o espaço social, um espaço em que todo discurso normativo é um discurso de poder que estabelece e legitima desigualdades. Tendo essa conclusão como ponto de partida, assumo a necessidade de buscar outra concepção de sujeito, distinta tanto do sujeito abstrato como do sujeito produzido pelo poder, cujas implicações políticas sejam compatíveis com a formulação de critérios normativos que distingam inclusão de exclusão, e igualdades de desigualdades de gênero dentro e fora do movimento feminista.

4 Benhabib afirma que, em seu modelo narrativo, não há distinção entre self e identidade. A diferença atribuída a esses conceitos deve-se ao que ela chama de preconceito pós-moderno com a identidade, que presume que ela seja necessariamente uniforme e estável, enquanto o self seria fragmentado e provisório. No entanto, o objetivo de Benhabib é justamente contestar esse preconceito, sustentando que identidades sociais, como a mulher, não são necessariamente uma reificação de uma essência universal feminina (Benhabib, 1999, p. 353).
} 
Benhabib enfrentou diretamente o desafio de articular uma concepção de subjetividade cuja contextualização não comprometa o potencial crítico do feminismo.

Benhabib reconhece que, após os debates iniciais com Butler, suas divergências mostraram-se menores do que aparentavam ser nas primeiras discussões. Em obras posteriores a Problemas de gênero, como Bodies that matter: on the discursive limits of "sex" (de 1993) e Excitable speech: a politics of the performative (de 1997), Butler esclarece melhor sua concepção de ressignificação, em relação à qual Benhabib não faz qualquer objeção. A divergência teórica que persiste entre as autoras, porém, é relevante e pode ser sintetizada na seguinte questão: "pode haver ressignificação e resistência sem comunicação?” (Benhabib, 1999, p. 340). A resposta de Butler é afirmativa, e a de Benhabib, negativa.

Para Butler, a ressignificação é produto da relação do sujeito com o discurso. A perspectiva dos participantes da performance, seja a que confirma a norma como a que a ressignifica, não é relevante, de modo que não há como diferenciar performances irrefletidas de atitudes deliberadas que buscam determinado resultado político. Por isso, Benhabib (1999, pp. 340-41) sustenta que Butler sacrificou a intencionalidade da ação política e da subversão juntamente com o sujeito ${ }^{5}$.

A impossibilidade de articular a intencionalidade do sujeito com a ressignificação fica bastante clara no exemplo da drag queen, uma vez que, como foi dito, sua performance não resulta de uma disposição deliberada de ressignificar a norma. A ressignificação resulta da expressão de sua performance que desestabiliza os padrões hegemônicos, a despeito da intenção do sujeito engajado na performance.

\footnotetext{
5 Susan Bordo viu na forma linguística de compreender a significação cultural associada à celebração da subversão como sintoma de volutarismo e não determinismo. Para Bordo, Butler sugere que a resistência à opressão de gênero deriva simplesmente da decisão de parodiar as normas de gênero (Bordo, 1993, pp. 293-94).
} 
A perda da intencionalidade é uma consequência necessária, conforme aponta Benhabib, da desconfiança de Butler em relação a todo discurso normativo, inclusive a qualquer concepção de igualdade. Por isso, não há para o sujeito performativo de Butler a possibilidade de questionar valores e de conceber arranjos sociais e políticos mais igualitários, uma vez que, para isso, Butler teria de conceber a ressignificação como uma ação política voltada não apenas para os discursos de poder, mas também para outros sujeitos, em relações de comunicação ${ }^{6}$.

Esse é exatamente o projeto de Benhabib. Sua ideia fundamental é a de que nós somos constituídos por histórias das quais somos ao mesmo tempo autores e ouvintes; nós nascemos em uma "teia de relações e histórias humanas", metáfora que toma emprestada de Hannah Arendt (2000, pp. 194-200) para designar o feixe de conexões invisíveis entre os seres humanos que constituem o "horizon52 te" de suas interações. Horizonte que, por sua vez, corresponde, em seu sentido fenomenológico, às referências que tomamos como certas quando estamos no mundo. Assim, as redes de relações humanas e as histórias que emergem dessas relações constituem o pano de fundo no qual a vida humana se desenvolverá (Benhabib, 2003, p. 112) ${ }^{7}$.

\footnotetext{
6 Em seu trabalho mais recente, Butler introduz a relação com o Outro no processo de formação da subjetividade. Mas ela o faz distanciando-se do quadro teórico que embasou sua tese em Problemas de gênero. Nessa mudança, Butler se aproxima de E. Levinas, a fim de complementar a relação do sujeito com o poder com uma concepção de intersubjetividade capaz de embasar uma ética da não violência. Ver, especialmente, Levinas (2011 [1961]) e Butler (2004 e 2005).

7 O conceito de "teia de relações humanas" que Seyla Benhabib mobiliza para formular seu conceito de self narrativo foi elaborado por Hannah Arendt em A condição humana. Benhabib, porém, apropria-se desse conceito a propósito de sua discussão sobre a contextualização do sujeito, tendo em vista o problema do sujeito do feminismo. Por isso, seu foco está nas narrativas de gênero nas redes de interlocução (webs of interlocution, na expressão de Benhabib), uma questão que não foi abordada por Arendt. Trata-se, portanto, como diz Benhabib, de uma apropriação do conceito de Arendt que pretende levá-lo para além da própria Arendt, mas que reivindica ser consistente com o pensamento da autora (Benhabib, 2003, p. 214).
} 
Benhabib insiste, porém, que esses horizontes não são o componente determinante da subjetividade. Embora estejamos imersos nas redes que forjam esse horizonte, nossa identidade será constituída de acordo com as atitudes que tomamos em relação a ele (Benhabib, 1999, p. 346). O sujeito, portanto, não se define por um núcleo coerente e estável de significados que já está pronto antes de nascermos, mas sim pela capacidade de atribuirmos significado à nossa história de vida, à nossa capacidade de narrar. Mas essa capacidade é sempre exercida no contato intersubjetivo em um contexto em que já há vários significados socialmente validados (Benhabib, 1999, p. 346).

As identidades de gênero, dessa perspectiva, correspondem também a narrativas, geralmente às primeiras narrativas em que nos vemos envolvidos, e, por isso, costumam ser o ponto de partida para a construção das demais macronarrativas. Essas primeiras narrativas, porém, não equivalem à essência humana, não formam um núcleo imutável, uma vez que a capacidade de narração não presume ou se relaciona ao assunto da história que é contada; ela se refere somente ao processo formal de narração (Benhabib, 1999, p. 344).

Benhabib, portanto, não corrobora o sujeito pré-social e reificado, alvo das críticas de Butler. Afinal, o self narrativo é uma criação conjunta de todos os participantes da rede da qual fazemos parte. E essa criação será sempre precária e provisória porque nossa narrativa será sempre revisada. Nem mesmo nossas lembranças passadas são estáveis, pois elas somente podem ser revividas através de narrativas do presente (Benhabib, 1999, p. 346).

O self narrativo, em suma, constitui-se na própria ação, entendida como um processo comunicativo que perdura durante toda a existência. Nesse processo, somos narradores de nossa própria história, mas isso não nos dá total domínio sobre quem somos ou seremos, pois nós não somos os únicos autores dessas narrativas, as quais são cons- 
truídas em relações intersubjetivas em que nossos interlocutores interpretam nossa fala e tentam conciliar nossa história de vida com a narração de sua própria história. Isso significa que ninguém é livre para inventar a si mesmo, pois nossas narrativas afetam e condicionam as das demais pessoas e vice-versa.

Segundo Benhabib, sua concepção de sujeito distingue-se da de Butler não porque a de Butler seja contextualizada e a sua abstrata, como acredita Butler, mas sim em razão da forma como concebem o contexto. Em Butler, ele é necessariamente assimétrico, é tecido unicamente por relações de poder, enquanto em Benhabib as redes de relacionamento envolvem assimetrias e diferenças, bem como simetrias e igualdades (Benhabib, 2003 [1996], p. 112). São teias de comunicação cuja dinâmica é marcada pela pluralidade, entendida aqui no sentido arendtiano, ou seja, como "condição da ação humana pelo fato de sermos todos os mes54 mos, isto é, humanos, sem que ninguém seja exatamente igual a qualquer pessoa que tenha existido, exista ou venha a existir" (Arendt, 2000, p. 16).

Assim, as relações intersubjetivas nas redes de comunicação em Benhabib comportam ao mesmo tempo a singularidade e a igualdade entre os seres humanos. Por isso, sua concepção de subjetividade distingue-se da homogeneização e reificação da identidade, que anularia a condição da pluralidade, sem com isso reduzir todo discurso normativo a discurso de poder, como faz Butler. Afinal, o espaço social do qual esses discursos emergem, embora sejam atravessados por assimetrias e diferenças, são também permeados pela igualdade que permite a comunicação entre os seres humanos (Benhabib, 1999, pp. 112, 343).

No entanto, conforme assinala Amy Allen (2007), embora Benhabib tenha avançado muito na contextualização do sujeito, a conexão entre identidade e dominação de gênero no self narrativo parece ter sido subestimada em 
seu argumento. Isso porque o núcleo do self, a capacidade de narrar, é descrita como uma capacidade neutra quanto ao gênero. O problema disso está em que se considerando

[...] o quão difusamente nossa realidade cultural e social é formada pela diferença e dominação de gênero, deve-se esperar que essas capacidades também sejam "generificadas" [gendered]. [...] Apelar simplesmente para o processo estrutural de individuação e socialização de capacidades formais do self não leva adiante a disputa [entre Butler e Benhabib]. [...] Os processos formais e estruturais são também articulados de um ponto de vista situado e contextualizado, e perfilado por relações de poder de gênero. [...] Benhabib está, sem dúvida, correta em argumentar que o desafio da teoria crítica feminista é responder à questão: "como podemos ser constituídos pelo discurso sem sermos determinados por ele"?. No entanto, pelo fato de sua concepção obscurecer o papel que o gênero e o poder cumprem na constituição do self narrativo, ela subestima a profundidade do problema (Allen, 2007, pp. 169-70).

A consequência política do selfneutro quanto ao gênero é simplificar as relações entre gênero e poder, o que permite a Benhabib chegar com certa facilidade a uma conclusão otimista acerca da possibilidade de conciliar a contextualização do sujeito com a intencionalidade na ação política.

A fim de superar essa fragilidade no argumento de Benhabib, seria necessário "generificar" (to gender) a própria capacidade de narrar, pois, como foi dito, as diferenças de gênero a impactam tanto quanto o conteúdo da narrativa (Allen, 2007, p. 170). Mas, para enfrentar essa questão, seria preciso explorar a relação entre corpo e subjetividade mais profundamente do que Benhabib o faz, uma vez que a materialidade corporal e sua relação com essências naturais, metafísicas ou científicas inerentes ao masculino ou ao 
feminino estão invariavelmente presentes nos discursos de diferença e dominação de gênero.

A limitação da "corporificação" (embodiment) do selfnarrativo de Benhabib parece estar associada à relação problemática entre corpo e política em Hannah Arendt. Ao inspirar-se na concepção de self de Arendt, Benhabib parece ter herdado dela um self contextualizado, mas ainda assim não suficientemente enraizado em seu corpo.

Hannah Arendt não ignora o corpo, como fazem tantos teóricos políticos, mas o vê como um fardo inescapável, que representa uma ameaça à pluralidade (Zerilli, 1995, p. 171; e Tambornino, 1999, p. 172). Em A condição humana, o corpo do animal laborans o aprisiona no ciclo interminável da natureza, a partir do qual nada de novo é criado. O corpo nos impõe necessidades previsíveis e escravizantes. Além disso, não remete à relação com o mundo. $\mathrm{O}$ corpo nos isola $\mathrm{e}$ nos concentra na atividade de mantê-lo em funcionamento 56 (Arendt, 2000, pp. 90-92). É, portanto, radicalmente diferente da política.

A política está relacionada ao novo em Arendt justamente porque se realiza por meio de atos e vontades que poderiam ser diferentes, que são imprevisíveis. O corpo, conforme sua descrição, é, ao contrário, o lugar dos apetites e pulsões que não nos deixam escolha. Mas não é esse tipo de desejo que move a ação. A política é feita da vontade, e não da necessidade (Arendt, 1981, p. 35).

No entanto, há também outra vertente na abordagem do corpo em Arendt (2000, p. 297), em que sua relação com condicionantes sociais tem maior destaque, como quando afirma que a modernidade alterou nossa relação com o mundo, o funcionamento da vida e até mesmo o corpo dos cidadãos. Em $A$ vida do espírito, Arendt aprofunda essa ideia aproximando-se do "filósofo da carne", como chama Merleau Ponty, para recuperar a ideia de "boa ambiguidade", ou seja, a condição de sermos simultaneamente sujeito 
e objeto, perceptores e percebidos, corpo e mente (Arendt, 2002, pp. 27 e ss. $)^{8}$. No entanto, no conjunto de sua obra prevalece a ideia de que

[...] pensamento e política [são definidos] em oposição ao corpo. [Nas] formulações em que enfatiza a fraqueza e imutablidade do corpo, essa pode ser uma posição viável. No entanto, suas outras formulações, que reconhecem a indisciplina do corpo e seu entrelaçamento na sociedade, tornam sua desatenção política com o corpo muito menos viável (Tambornino, 1999, p. 185).

Como se vê, há tendências contraditórias na forma como Arendt aborda o corpo e sua relação com a sociedade e a política. Essas contradições, por sua vez, afetam diretamente a consistência de sua concepção de política. Esse é justamente o tipo de incongruência que Benhabib explora para, em suas palavras, usar "Arendt contra Arendt".

No entanto, esse projeto de Benhabib parece mais frutífero quando busca encontrar a normatividade intrínseca no argumento de Arendt do que quando se trata de contextualizar o corpo. Isso porque o corpo contextualizado arendtiano tampouco é sexuado. As diferenças sociais não incluem diferenças de gênero, pois estas não são relevantes politicamente em nenhuma das concepções de corpo que propõe (Kristeva, 1986, p. 191).

Algumas teóricas feministas consideram que isso não seja propriamente uma falha, mas sim uma inspiração para a desconstrução do corpo biológico. Linda Zerilli, por exemplo, afirma que:

\footnotetext{
8 Agradeço a Seyla Benhabib por me indicar que a compatibilidade entre sua concepção de self narrativo e a subjetividade corporificada de Beauvoir está sugerida na apropriação que Arendt faz de Merleau-Ponty em A vida do espírito. Conforme se verá na seção seguinte, Beauvoir recorre ao mesmo filósofo para articular corpo e mente, sujeito e objeto e liberdade e opressão.
} 
Quando as feministas se apressam em corrigir a "cegueira de gênero" em Arendt, elas também podem se comprometer com a reinscrição da diferença sexual, que muito frequentemente serve como uma tela que encobre a experiência de ter um corpo. Na leitura do "gênero" com base na concepção não feminista de Arendt de cidade-estado, por exemplo, as feministas citam a diferença sexual como se elas tivessem um significado simbólico e histórico predeterminado. Mas elas tem? Se Judith Butler estiver certa quando diz que não há referência a um corpo "que não seja ao mesmo tempo uma futura formação daquele corpo”, as referências feministas à falta de corpos sexuados nas cidades-estado de Arendt são descritivas e, enquanto tal, performativas: feministas dão forma ao próprio corpo que descrevem e então os materializam. Mas a crítica feminista, como eu a entendo, deve desprender-se da ideia que o gênero possui em nosso imaginário cultural e no nosso quadro interpretativo. E a cegueira de Hannah Arendt em relação ao gênero pode, na realidade, nos ajudar nessa difícil tarefa (Zerilli, 1995, p. 188; grifo no original).

A apropriação feminista de Arendt que Zerilli propõe está embasada na relação entre corpo e subjetividade tal como proposta por Judith Butler. Para Benhabib, porém, essa interpretação não é atraente em função de suas implicações no conceito de autonomia e igualdade de gênero. Conforme comentado anteriormente, é precisamente por essa razão que Benhabib busca em Arendt recursos teóricos para formular uma concepção alternativa de self.

Assim, ao formular seu conceito de self a partir da concepção de intersubjetividade de Arendt, sem aderir à leitura feminista pós-moderna, Benhabib fica sem recursos para corporificar e, sobretudo, para "generificar" (to gender) seu self narrativo. 
O dilema que decorre dessa análise parece sugerir que não há alternativas intermediárias que superem a polarização epistemológica que o debate entre Butler e Benhabib representa. Nesse cenário, a melhor estratégia para fugir dessa polarização parece ser a combinação de alguns elementos de cada um desses polos ${ }^{9}$.

Mas, se não parece haver rota de fuga na tensão entre contextualização corporificada do sujeito e a justificação de concepções de autonomia e igualdade de gênero, é porque nesse debate o sujeito iluminista e o pós-moderno aparecem como as únicas opções no cardápio. Felizmente, porém, o menu é mais variado.

\section{Simone de Beauvoir: a "mulher" como o segundo sexo}

Eu disse como esse livro [O segundo sexo] foi concebido; quase fortuitamente, querendo falar de mim, percebi que precisava descrever a condição das mulheres [...] Tentei pôr em ordem no quadro, à primeira vista incoerente, que se ofereceu a mim: em todo caso, o homem se colocava como o Sujeito e considerava a mulher como um objeto, o Outro. [...] Um dos mal-entendidos que meu livro suscitou foi que se pensou que nele eu negava qualquer diferença entre homens e mulheres: ao contrário, ao escrevê-lo medi o que os separa; o que sustentei foi que essas dessemelhanças são de ordem cultural e não natural. Contei sistematicamente como elas se criam, da infância à velhice, examinei as possibilidade que este mundo oferece às mulheres, as que lhes são recusadas, seus limites, suas oportunidades e faltas de oportunidade, suas evasões, suas realizações.

Simone de Beauvoir

Na passagem acima de sua biografia, escrita em 1963, Beauvoir (2009, pp. 210-11) sintetiza os dois problemas centrais de $O$ segundo sexo. Um deles já está sugerido no próprio

9 Nancy Fraser escolhe exatamente este último caminho. Ver nota 3 deste artigo. 
título: a mulher é o não sujeito, é o Outro, o segundo. O outro problema diz respeito à forma como justifica esse argumento. Ser o Outro não é uma condição determinada pela natureza. É a cultura que define a experiência da mulher desse modo. Essas ideias, porém, nem sempre foram interpretadas dessa forma. Em parte porque a recepção de $O$ segundo sexo entre seus contemporâneos foi marcada por hostilidades pessoais. Acusaram-na de ser "neurótica, frustrada, uma deserdada, uma mulher-macho, uma invejosa, amargurada repleta de complexos de inferioridade com relação aos homens, com relação às mulheres, roída pelo ressentimento" (Beauvoir, 2009, p. 214). Essas reações agressivas poderiam ser explicadas com sua própria tese sobre a condição feminina, pois as críticas ao livro desqualificaram a autora como agente e intelectual (Moi, 1990, p. 23).

No entanto, há ainda outros dois fatores relevantes que podem ter conduzido a problemas de leitura e interpreta60 ção da obra. Um deles é justamente o que, segundo Nancy Bauer (2001, pp. 173-74), corresponde ao ponto no qual reside a originalidade da obra: os dois registros em que foi escrita. Um deles refere-se ao ordinário, ao cotidiano; e o outro, ao filosófico. Uma das primeiras resenhas do livro nos Estados Unidos, escrita por Elizabeth Hardwick (1953, p. 321), qualificou o livro como "brilhantemente confuso" exatamente por isso.

Finalmente, a última e importante razão que pode ter justificado a minimização da relevância filosófica da obra é o fato de a própria Beauvoir não ter reivindicado para si qualquer originalidade nesse campo. Foi ela mesma que se definiu como uma discípula de Sartre; o que, ironicamente, talvez possa ser também explicado com sua tese em $O$ segundo sexo. Ela se considerava original no campo da literatura, mas na filosofia afirmava ter aderido completamente às ideias de Sartre em $O$ ser e o nada e Crítica da razão dialética (Kruks, 1995, p. 80). Essa declaração foi tomada como ver- 
dade absoluta por muitos anos, e justificou boa parte das críticas que as feministas na década de 1970 e 1980 dirigiram a $O$ segundo sexo.

Entre as mais recorrentes está a de que Beauvoir teria aderido ao sujeito abstrato e voluntarista que subsiste em $O$ ser e o nada, o que comprometeria a análise das estruturas de poder que oprimem as mulheres. A consequência imediata disso seria a de responsabilizar a mulher pela própria opressão, de qualificar sua subordinação como má-fé em sentido sartreano, ou seja, à escolha de renunciar ao ônus da liberdade para eximir-se da responsabilidade por suas ações.

Outra crítica frequente refere-se aos modos como Beauvoir relaciona corpo e subjetividade, em particular nos capítulos sobre biologia e maternidade. Segundo algumas leituras, Beauvoir trata o corpo como algo sujo e indesejado, que aprisiona a mulher em suas funções biológicas, o que, em última análise, implicaria abraçar o determinismo biológico que a mais célebre frase do livro, " não se nasce mulher, torna-se mulher”, parece desmentir (Pillardi, 1995, pp. 34-35).

Tais críticas, quase em uníssono, conferiram a Beauvoir, dentro do feminismo do final dos anos de 1970 e na década de 1980, o status de uma figura a ser venerada como uma musa, a "mãe" da segunda onda feminista, uma pioneira a ser respeitada, mas cujas ideias remeteriam a um feminismo longínquo e ultrapassado (Kruks, 1992, pp. 94-96).

No entanto, apesar de declarar-se publicamente como discípula de Sartre, as divergências filosóficas com seu parceiro não eram propriamente secretas. Uma leitura atenta de $O$ segundo sexo já sinaliza que Beauvoir está mais alerta para o impacto que as assimetrias sociais produzem na liberdade do que Sartre admitira estar, particularmente em $O$ ser e o $\operatorname{nada} a^{10}$.

\footnotetext{
${ }^{10}$ A liberdade voluntarista em $O$ ser e o nada será atenuada à medida que Sartre se engaja em desenvolver uma filosofia social, que somente seria articulada completamente em Dialética da razão (de 1960). Esse projeto, como assinala Sonia Kruks,
} 
Em sua biografia publicada na década de 1960, também aparecem divergências filosóficas importantes entre eles no que se refere à liberdade. Nessa obra, Beauvoir menciona cartas trocadas com Sartre em 1940, em que discutiam a possibilidade de a opressão aniquilar a liberdade, de modo que não mais fizesse sentido falar em má-fé do oprimido. $\mathrm{O}$ exemplo com qual Beauvoir contesta Sartre é o da mulher em um harém: "que transcendência é possível a uma mulher trancada em um harém?", questiona ela. Vinte anos depois, Beauvoir continuou corroborando essa crítica ao voluntarismo de Sartre, mas admitiu que, quando discutiram em 1940, ela não estava pronta para abdicar do individualismo com que ambos estavam engajados naquela época.

Apesar de essas divergências estarem explícita ou implicitamente presentes na obra de Beauvoir, foi somente após a sua morte, em 1986, que surgiu uma considerável desconfiança em relação à fusão filosófica declarada entre ela e 62 Sartre. Sylvie Le Bon de Beauvoir, a filha adotiva de Simone, autorizou a publicação de diários, cartas e outros escritos privados que revelaram, além de seus relacionamentos sexuais com mulheres, muito mais distanciamentos filosóficos de Sartre do que Beauvoir esteve disposta a admitir em público (Kruks, 1992 pp. 95 e ss.; Simons, 1995, p. 4).

Esse novo material ensejou o que se chama de "renascimento dos estudos de Beauvoir" da década de 1990. A mãe da segunda onda ${ }^{11}$, ao mesmo tempo respeitada e ultrapas-

foi em grande medida influenciado pela crítica não explícita que Beauvoir dirige ao voluntarismo sartreano em seus ensaios Pyrrhus et Cinéas (de 1944), Ética da ambiguidade (de 1947) e, especialmente, em O segundo sexo (de 1949). Assim, diz Kruks, no que se refere ao tema da liberdade e da opressão, foi Beauvoir quem influenciou o pensamento de Sartre (e não o inverso), embora nenhum dos dois estivesse disposto a admitir isso publicamente. Ver Kruks (1995, p. 82).

${ }^{11}$ Beauvoir rejeitou o posto de "mãe da segunda onda". Em entrevista concedida à tevê francesa em 1975, ela afirma que a origem da segunda onda deve ser atribuída aos protestos anti-Vietnã e anti-coloniais nos Estados Unidos e na França. Seu livro, porém, afirmou, foi apropriado nesse contexto pelo movimento feminista, tendo contribuído para articular o discurso feminista da segunda onda, com o 
sada, passou a ser reconhecida por um crescente número de filósofas e teóricas feministas como uma pensadora original e atual, que oferece ferramentas teóricas vigorosas para os debates feministas da chamada terceira onda. Esquematicamente, pode-se dizer que a originalidade filosófica encontrada em Beauvoir a partir dessa fase concentra-se em dois tópicos: a intersubjetividade do sujeito, e a relação inerente entre corpo e subjetividade. Aspectos estes que,entrelaçados, constituem a subjetividade situada, concepção que ela mobiliza em sua análise da condição feminina.

\section{A intersubjetividade do sujeito}

As divergências entre Sartre e Beauvoir acerca da relação entre opressão e liberdade estão relacionadas ao modo como cada um deles compreende a relação com o Outro no processo de constituição do sujeito.

Sartre sintetiza essa relação na célebre frase da personagem Garcin: “o inferno são os outros”. A frase é dita na peça Entre quatro paredes, ambientada no inferno. É ali que as três personagens, Garcin, Estelle e Inês, se conhecem e interagem. Todos acreditam ter boas razões para estar no inferno. Mas, para surpresa geral, não encontram o diabo ou qualquer outro torturador que os aguardaria para lhes fazer pagar por seus pecados. O inferno é, sem dúvida, torturante, mas são eles próprios os torturadores uns dos outros. $\mathrm{O}$ inferno consiste justamente na impossibilidade de escapar dessas relações de hostilidade. Em alguns momentos, a dinâmica da interação entre os personagens torna-se mais amistosa, aproxima-se da cooperação, mas ela inevitavelmente termina degenerando-se em algum tipo de polarização: seja de dois contra um ou de todos contra todos (Bauer, 2001,

qual ela somente viria a se aliar mais de vinte anos após a primeira edição de $O$ segundo sexo. Ver entrevista Pourquoi je suis feministe? Disponível em: <www.ina.fr/ video/CAA00016153>; último acesso em: 14 abr. 2015. 
pp. 119 e ss.).

"O inferno são os outros" sintetiza em uma frase a ideia central de Sartre acerca do encontro humano: a impossibilidade do reconhecimento mútuo, uma ideia filosoficamente articulada na seção "O olhar" de $O$ ser e o nada. Nessa obra, Sartre apresenta a cena do reconhecimento propondo que imaginemos que

[...] por ciúmes, curiosidade ou vício, eu tenha chegado ao ponto de grudar meu ouvido em uma porta ou olhar pelo buraco de uma fechadura. Estou sozinho e ao nível da consciência não tética [de] mim. Significa, em primeiro lugar, que não há um $e u$ a habitar minha consciência. Nada, portanto, a que possa relacionar meus atos a fim de qualificá-los. Esses atos não são de modo algum conhecidos; eu sou meus atos, e, apenas por isso, eles carregam em si sua total justificação. [...] Significa que, detrás desta porta, uma cena se apresenta como "para ser vista", uma conversa como "para ser ouvida”. A porta, a fechadura, são ao mesmo tempo instrumentos e obstáculos: mostram como "para manusear com cuidado"; a fechadura revela-se como "para olhar de perto e meio de viés" etc. Assim sendo, "faço o que tenho de fazer"; nenhum ponto de vista transcendente vem conferir a meus atos um caráter de algo dado sobre o qual fosse possível exercer-se um juízo: minha consciência adere aos meus atos, ela é os meus atos, os quais são comandados somente pelos fins a alcançar e os instrumentos a empregar. $[\ldots]$

Eis que ouço passos no corredor: alguém me olha. Que significa isso? Fui de súbito atingido em meu ser e surgem modificações essenciais em minhas estruturas-modificações que posso captar e determinar conceitualmente por meio do cogito reflexivo (Sartre, 
2011, p. 334).

A consciência não reflexiva que espia pelo buraco da fechadura não pensa sobre qualquer implicação de seus atos. Mas, quando percebe-se captada pelo olhar do Outro, sofre modificações estruturais. O que é olhado é um ego "para o Outro", é um ego reificado. O olhar do outro produz uma mudança ontológica no self, que é registrada como vergonha ou orgulho, e esses sentimentos revelam a mim não apenas que eu sou um objeto fixo da percepção do Outro, mas também que o Outro me percebe como apenas isso. E é a necessidade de aliviar a minha vergonha, provando que eu sou mais do que apenas um ser reificado que motiva minha relação subsequente com o Outro, ou seja, que motiva a luta de vida e de morte de Hegel (cf. Bauer, 2001, p. 109).

Para escapar da condição de objeto aprisionado pelo olhar do Outro, é preciso reivindicar ser um sujeito. O modo de fazê-lo é olhar de volta ao Outro, de modo a reduzi-lo a um objeto em meu mundo. Ao capturar o Outro com meu olhar, eu recupero a mim mesmo, uma vez que não poderia ser objeto para um objeto. Assim, tornar o Outro objeto para mim é o modo de tornar-me sujeito. É preciso deixar de ser um objeto para tornar-se sujeito; e isso, para Sartre, somente é possível tornando o Outro objeto. Assim, na dialética de Sartre, apenas um sujeito sobrevive. Mas isso significa, então, que não há espaço para identificar-se com a liberdade do Outro, que não há espaço para a intersubjetividade?

Para Sartre, esse é o ideal do amor. Mas esse ideal é mera fantasia. O amor está condenado ao fracasso porque exige que o Outro destine sua liberdade à escolha de amar. Mas ao despender a liberdade nisso, deixa de ser um sujeito e, desse modo, não será mais capaz de amar. Só o sujeito é capaz de amar, mas, ao escolher amar, converte-se em objeto, o que torna o amor impossível. A saída desse impasse supõe a possibilidade de nos constituirmos simultaneamente como 
sujeito e objeto. Mas em Sartre isso é inviável, pois o olhar do outro me torna um objeto e faz do Outro um sujeito; e meu olhar de volta inverte os papéis. Disso decorre que, em Sartre, reconhecer outra pessoa é o mesmo que reificá-la (cf. Bauer, 2001, pp. 121 e ss.).

Em Simone de Beauvoir, a cena do encontro com o Outro é apresentada de modo distinto, o que traz importantes consequências epistemológicas e ontológicas para sua reflexão sobre liberdade, opressão, reconhecimento e sobre a condição feminina. Essas diferenças já se anunciavam nos trabalhos filosóficos anteriores a $O$ segundo sexo, mas foi somente nesta última obra que sua própria leitura da dialética do senhor e do escravo foi completamente articulada.

Em relação ao conceito de liberdade, Beauvoir (1940, 1947) sugere em Pyrrhus et Cinéas e em Ética da ambiguidade que existem situações em que a opressão não deixa espaço para a ação, de modo que não resistir à reificação, não se 66 engajar na luta de vida e morte, não será, para Beauvoir, necessariamente má-fé (Kruks, 1995, p. 83). Em O segundo sexo, Beauvoir é ainda mais enfática em relação ao peso que confere às constrições e assimetrias sociais. Enquanto em $O$ ser e o nada, Sartre apresenta uma ideia de liberdade indestrutível, a ponto de afirmar, em meio à Segunda Guerra Mundial, que o judeus continuavam livres porque lhes restavam escolhas acerca das atitudes a tomar diante de seus perseguidores, Beauvoir acentua o papel que o poder exerce na formação da subjetividade. Esse é um dos pontos que a aproxima mais de Merleau-Ponty do que de Sartre, uma vez que é no primeiro em quem Beauvoir se inspira para desafiar a ideia de que as situações sociais modificam a própria liberdade, e não apenas a sua exterioridade.

A ênfase na assimetria entre duas subjetividades a conduz a uma descrição da cena do reconhecimento bastante diferente da de Sartre. Em O segundo sexo, o encontro com o Outro não se assemelha a uma troca (ou revide) de olhares. 
É um encontro mediado por instituições, como a do casamento, por exemplo. Quando essas instituições privilegiam uma das partes de modo significativo, a sua vantagem pode fixar a outra parte na posição de objeto (cf. Kruks, 1995, p. 84; Bauer, 2001, p. 216). Desse modo, a própria liberdade seria modificada estruturalmente.

A característica principal dessa cena alterada é a ausência de reciprocidade. Ou seja, é um cenário em que o que está em questão não é apenas a alteridade, mas a subordinação, a reificação que não é recíproca.

Em Sartre, conforme já foi comentado, o reconhecimento mútuo não é possível, uma vez que, para afirmar-me como sujeito, preciso negar essa condição ao Outro, e vice-versa. No entanto, ambas as liberdades são ontologicamente iguais no que se refere à capacidade de reagir à reificação e revidar o olhar. Mas o que Beauvoir diz a respeito da mulher é precisamente o oposto. Ao sustentar que a mulher é o Segundo, ela afirma que a mulher não é apenas o Outro; é o outro desigual (cf. Kruks, 1995, p. $85 ; 1992$, pp. 100 e ss.). Trata-se de uma desigualdade socialmente construída, uma construção social situada na concretude do corpo feminino.

\section{Corpo e subjetividade}

Muitas interpretações feministas dessa abordagem do corpo biológico em Beauvoir veem traços de essencialismo em suas reflexões. Outras leituras atentam para o argumento de Beauvoir de que as características biológicas somente são inferiorizadas em razão de significados que as normas sociais lhes atribuem, e não em razão de sua constituição física por si mesma. Essa última visão, por sua vez, parece sugerir que a relação entre corpo e sociedade em Beauvoir é muito próxima à conhecida distinção entre sexo e gênero que Rubin proporia em meados da década de 1970. No entanto, ambas as interpretações perdem de vista o rigor do conceito de 
situação que entrelaça profundamente corpo e subjetividade (Moi, 2001 [1999], pp. 59 e ss.). A materialidade biológica do corpo é um elemento importante da subjetividade, mas não a antecede nem tampouco define um destino. O corpo "é uma situação, é nossa tomada de posse do mundo e um esboço de nossos projetos" (Beauvoir, 1980, v. 1, p. 54).

O enraizamento corporal em Beauvoir é o elemento central para compreender sua tese sobre a condição feminina. Ser o Segundo não é apenas um efeito de constrições externas das quais a mulher pode se libertar como se retirasse uma camada estranha à sua subjetividade. Ser o segundo sexo é a condição de uma subjetividade corporificada. Mas o corpo comporta a ambiguidade de estar ao mesmo tempo sujeito à natureza e à cultura. Por isso, diz Beauvoir, "não é enquanto corpo, mas enquanto corpo submetido a tabus, a leis, que o sujeito toma consciência de si mesmo e se realiza" (Beauvoir, 1980, v. 1, p. 56). Mas o corpo subme68 tido a tabus em Beauvoir não é algo que o sujeito possua, é o que o sujeito é, como em Merleau-Ponty. Isso não significa que o sujeito seja um objeto físico, mas, sim, que o corpo tampouco o é. Ele é um "nó de significações rivais" que moldam nossa perspectiva no mundo, mas que está também engajado em uma relação dialética com seu contexto. Nossa experiência corporificada é constituída nessa interação (Merleau-Ponty, 1999, pp. 207-10).

Como se vê, não há em Beauvoir a redução da materialidade do corpo aos discursos que lhe atribuem significados ou vice-versa. Trata-se de uma combinação dessas duas dimensões da subjetividade que se condicionam reciprocamente e que somente adquirem significado nessa interação (Ward, 1995, p. 231). O corpo, portanto, corresponde à consolidação histórica de nosso modo de viver no mundo e do mundo viver conosco (Moi, 2001, p. 68).

Em Beauvoir (1980, v. 2, p. 395), porém, essa concepção de subjetividade corporificada convive com a sua tese 
sobre a alienação corporal da mulher, ou seja, a de que ser o Segundo implica ser apartada de seu corpo. Essa posição parece, ao menos à primeira vista, contradizer a ideia de que o corpo é uma situação. No entanto, essa contradição é aparente porque Beauvoir jamais separa ontologicamente corpo e mente. A ideia de que o corpo pode ser algo exterior à mulher busca apenas destacar que o contexto cultural e social reifica seu corpo a ponto de separá-lo do sujeito. Mas dessa separação não resulta uma mente expropriada de seu corpo, mas sim uma subjetividade deteriorada em seu conjunto (Arp, 1995, 168-69).

Deteriorada, porém, não equivale a anulada. Seu distanciamento do voluntarismo de Sartre de $O$ ser e o nada não a conduziu ao determinismo social. Embora considere que Sartre exagere no uso que faz de seu conceito de má-fé, ela o incorpora em cores mais suaves.

\section{Má-fé, liberdade e opressão}

Entre as passagens mais criticadas de $O$ segundo sexo por autoras feministas é a seção intitulada "narcisismo", especialmente pelo modo como aborda a questão da cumplicidade feminina com a sua opressão.

Segundo ela, o narcisismo se apresenta à mulher como um modo razoavelmente acessível de reunir-se ao seu corpo. Mas essa reunião não realiza a síntese entre corpo e subjetividade, ao contrário, é uma integração que se realiza às expensas desta última. Não é ao corpo vivido que a mulher se integra fazendo de seu próprio corpo objeto de cultivo e idolatria; é ao corpo passivo, ao corpo-coisa (Arp, 1995, p. 165). É por isso que o narcisismo pode ser ao mesmo tempo considerado uma forma de reação e cumplicidade com a própria opressão. É reação porque busca a integração com o corpo, e é cumplicidade porque, ao incorporar-se como Outro, foge da liberdade e de seu ônus, a responsabilidade.

Algumas feministas viram nessa noção de cumplicidade 
a adesão de Beauvoir a uma concepção de liberdade voluntarista. Mas respostas a essa leitura podem ser encontradas em inúmeras passagens de $O$ segundo sexo, que assinalam a desigualdade e ausência de reciprocidade entre o homem e a mulher, conforme comentado anteriormente. $\mathrm{O}$ ponto que Beauvoir pretende assinalar é antes o de que as escolhas disponíveis à jovem mulher, que se percebe alienada de seu corpo, não são muitas; e, nesse contexto, o narcisismo é uma das formas de reagir a ela; ainda que seja uma reação carregada de ambiguidades e, na maior parte dos casos, de certa dose de má-fé.

Mas, se é assim, parece que Beauvoir evitou a liberdade voluntarista à custa de uma restrição bastante excessiva da liberdade, que não parece deixar muitas rotas alternativas para a ação individual. De fato, Beauvoir não tem esperança na capacidade de uma mulher individualmente vencer a opressão feminina. Embora seja simpática a iniciativas indi70 viduais desse tipo, ela afirma que estão todas condenadas ao fracasso (Beauvoir, 1980, v. 2, p. 393). A "mulher independente", que retrata no último capítulo do livro, não é produto de um projeto individual, e sim do conjunto de instituições e práticas culturais do mundo em que vive.

Contra a opressão construída socialmente, a transformação individual é indispensável, mas insuficiente. Isso porque, como assinala Kruks (1995, p. 90), “'minha' situação não é estritamente 'minha', mas parte de uma situação mais geral que transcende a minha experiência imediata [...] A liberdade é, [portanto], uma relação de mão dupla, inseparável de nossa inserção no mundo". Por isso, para Beauvoir, a luta contra a opressão feminina pressupõe mudanças nas leis, instituições, costumes, opinião pública, nas condições econômicas e profissionais das mulheres. E essas mudanças não podem ser alcançadas individualmente.

É por isso que, nos parágrafos finais de $O$ segundo sexo, Beauvoir exorta as mulheres à ação coletiva, uma luta 
que emancipará não apenas as mulheres, mas também os homens. Isso porque, na dialética de Beauvoir, a luta contra a opressão é a luta pelo reconhecimento mútuo. Assim, como diz Bauer (2001, pp. 175, 233):

A rejeição de Beauvoir da retratação sombria das relações humanas transforma o encontro com o Outro não em uma condenação a uma luta interminável com o Outro, mas, sim, como uma oportunidade de captar duas importantes verdades: sobre nós mesmos, a de que somos fundamentalmente ambíguos, e sobre o Outro, especialmente a de que ele ou ela não é apenas um espelho.

O encontro com o Outro em Beauvoir em nada se assemelha ao inferno. Em sua interpretação da dialética do senhor e do escravo, a hostilidade em relação ao Outro é apenas uma das formas possíveis que o narcisismo pode assumir (Bauer, 2001, pp. 233-34). Essa é precisamente a forma em que assume na relação entre homem e mulher no diagnóstico que apresenta em $O$ segundo sexo. Mas essa não é, para Beauvoir, a dinâmica do reconhecimento genuíno.

O reconhecimento genuíno exige que admitamos nossa própria ambiguidade, a saber, a condição de sermos simultaneamente sujeito e objeto. Assim, a primeira luta não é com o Outro, mas com nós mesmos, uma luta contra o medo de nossa liberdade, o medo de abrir mão de uma relação segura com o mundo. Assumir nossa ambiguidade, portanto, implica, colocarmo-nos em risco. Esse é o primeiro passo para nos fazermos sujeitos.

No entanto, para isso é preciso também reconhecer no Outro um sujeito, o que para Beauvoir significa reconhecer sua alteridade, admitir que o Outro não nos refletirá. Trata-se, portanto, de um olhar para o Outro que não é mero narcisismo, como em Sartre. Afinal, para reconhecer o Outro como sujeito, é preciso abdicar de tentar manipu- 
lar ou controlar o julgamento que terá de mim. Será preciso expor-me ao seu livre julgamento. Trata-se, portanto, aqui também, de assumir riscos, em particular o risco de desapegar-se de uma autoimagem petrificada e segura, permitindo que o Outro nos diga quem somos (Bauer, 2001, pp. 204-05).

No reconhecimento genuíno de Beauvoir, porém, o que o Outro diz sobre nós tampouco é uma verdade petrificada, pois o que caracteriza o reconhecimento não é o conteúdo do que é dito sobre nós, mas sim a "disposição de continuar a conversa" (Bauer, 2001, p. 236). Assim, o que impulsiona a interação não é a busca desesperada e fracassada pelo espelho, como acontece com as personagens de Entre quatro paredes. A conversa é alimentada pelo risco de permitir ao Outro que exponha a nós mesmos as fantasias que construímos a nosso respeito na tentativa de nos esquivar de nossa ambiguidade.

72 A continuidade da conversa supõe investimento na linguagem e renúncia a imagens cristalinas e estáticas de nós mesmos e do Outro. Isso é o que é preciso para, nos termos de Beauvoir, assumir a responsabilidade de construir o mundo em coautoria. Ser coautora é, portanto, diferente de ser sujeito ou objeto absoluto. É habitar ambas as condições simultaneamente, assumindo-se como um cruzamento entre liberdade e reificação. Essa é, enfim, a cena do reconhecimento em que Beauvoir situa a relação de reciprocidade igualitária entre homens e mulheres.

$* * *$

No primeiro momento do debate entre Benhabib e Butler, ambas identificaram-se como radicalmente opostas. No entanto, o posterior desenvolvimento das discussões revelou que a oposição não é tão extrema quanto aparentava, especialmente no que se refere ao caráter discursivo do 
processo de formação do sujeito. Mas as diferenças que restam ainda são significativas. Enquanto em Butler, ao menos em seus primeiros trabalhos, a assimetria de poder não é empírica nem tampouco normativamente ultrapassável, em Benhabib a assimetria e a reciprocidade são articuladas em uma concepção de espaço social mais complexa e compatível com concepções normativas de igualdade ${ }^{12}$.

No entanto, se de um lado parece que Amy Allen está certa ao acusar Benhabib de reter elementos de abstração do self, a formalidade da capacidade de narrar não está relacionada, ao menos não principalmente, à sua desconexão com o discurso, conforme sustenta Allen, e sim à falta de uma concepção de corpo que integre discurso, matéria, poder e ação em uma mesma concepção de subjetividade.

Ao buscar elementos para conciliar poder e ação em Hannah Arendt, Benhabib não pôde evitar minimizar o papel do corpo no processo de formação da subjetividade. O corpo como mero organismo que nos impõe necessidades, ou o corpo socialmente condicionado, que podem ambos ser encontrados na obra de Arendt, não abrem caminho para destacar o papel das relações de gênero na constituição do self. Isso talvez não tenha sido um problema para uma autora que jamais se identificou com o feminismo, mas certamente o é para Seyla Benhabib.

No entanto, as lacunas feministas em Arendt, herdadas por Benhabib, podem ser facilmente preenchidas pela concepção de subjetividade de Simone de Beauvoir. Conforme foi comentado, o "renascimento dos estudos de Beauvoir", a partir da década de 1990, lançou luz sobre sua originalidade filosófica, negligenciada por feministas da segunda

\footnotetext{
${ }^{12}$ Em seus trabalhos sobre ética da não violência, como Precarious life (2004) e Giving an account of oneself (2005), Butler ultrapassa a equiparação entre discursos igualitários e discursos de poder. No entanto, conforme comentado na nota 6 , ela o faz aproximando-se de E. Levinas, mantendo, assim, diferenças acentuadas em relação às posições teóricas e políticas de Benhabib.
} 
onda, pelas pós- estruturalistas da terceira onda, e até mesmo pela própria Beauvoir.

Mesmo nesse contexto de ressurgimento da obra de Beauvoir, porém, a contribuição de sua concepção de "intersubjetividade do sujeito" e a relação entre corpo e subjetividade não recebeu a devida atenção no debate da teoria crítica feminista sobre o sujeito. A consequência disso parece ter sido consolidar a crença de que só temos duas alternativas: o sujeito moderno ou o pós-moderno. Ou talvez ainda uma terceira, qual seja, a de combinar elementos de ambos.

No entanto, um caminho mais direto e preciso para desfazer essa oposição pode estar sugerido no modo como poder, igualdade, corpo e ação política estão combinados na cena do reconhecimento de Beauvoir. De um lado, sua concepção mais branda de má-fé lhe permite introduzir mais poder nesse cenário, sem reduzi-lo a isso; e, de outro, 74 a dinâmica de sua dialética sugere a possibilidade normativa da igualdade. Essa igualdade é contextualizada, estabelecida por instituições e práticas culturais e sociais. É construída, assim como a igualdade de Arendt, mas é construída por agentes que tem um corpo que não é apenas um lócus de demandas da natureza, mas sim um corpo que é ao mesmo tempo faticidade e liberdade, um corpo político.

$\mathrm{O}$ reconhecimento genuíno requer que habitemos a nossa ambiguidade de sujeito e objeto; e nenhum dos aspectos dessa condição é separável do corpo. O corpo está, sem dúvida, associado à vulnerabilidade, ao risco. Mas isso não se deve meramente à fragilidade de sua matéria, e sim ao fato de o corpo ser inseparável da condição de sujeito e, portanto, do risco da ação.

Portanto, em Simone Beauvoir, mais do que qualquer capacidade de narrar, a ação, em particular a ação coletiva, supõe um sujeito que renuncia ao desejo narcisista de ver no Outro um espelho, aceitando-se como coisa diante dele; 
mas que, embora não transcenda essa condição, recuse a má-fé, assumindo também a responsabilidade de agir.

Nenhuma dessas ideias choca-se com as formulações de Seyla Benhabib. Ao contrário, seu projeto de situar o self, deixando espaço para ação e concepções normativas de igualdade de gênero, torna-se mais promissor e consistente com a incorporação da subjetividade corporificada de Simone de Beauvoir.

\section{Ingrid Cyfer}

é professora de Teoria Política do Departamento de Ciências Sociais da Universidade Federal de São Paulo (Unifesp).

\section{Bibliografia}

ALLEN, A. 2007. The politics of our selves: power, autonomy, and gender in contemporary critical theory. New York: Columbia University Press. ARENDT, H. 2000 [1958]. A condição humana. Rio de Janeiro: Forense Universitária.

2002 . A vida do espirito. Rio de Janeiro: Relume Dumará

ARP, K. 1995. "Beauvoir's concept of bodily alienation”. In: SIMONS, M.

Feminist interpretations of Simone de Beauvoir. Pennsylvania: Pennsylvania

State University Press.

BAUER, N. 2001. Simone de Beauvoir, philosophy Ẽ feminism. New York:

Columbia University Press.

BEAUVOIR, S. de. 1944. Pyrrhus et Cinéas. Paris: Gallimard. 1976 [1947]. Ethics of ambiguity. New York: Kensington Publishing. 1980 [1949]. O segundo sexo. Rio de Janeiro: Nova Fronteira. 2 v. 2009 [1963]. A força das coisas. Rio de Janeiro: Nova Fronteira.

BENHABIB, S. 1986. Critique, norm, and utopia: a study of the foundations of critical theory. New York: Columbia University Press. 1992. Situating the self. Gender, community and postmodernism in contemporary ethics. New York: Routledge. 1999. "Sexual difference and collective identities: the new global constellation”. Signs, v. 24, n. 2, pp. 335-61. 2003 [1996]. The reluctant modernism of Hannah Arendt. Lanham: Rowman \& Littlefield.

BORDO, S. 1993. Unbearable weight: feminism, western culture, and the body. Berkley: University of California Press. 
BUTLER, J. 1993. Bodies that matter: on the discursive limits of "sex". New York: Routledge. . 1997a. Excitable speech: a politics of the performative. New York:

Routledge. . 1997b. The psychic life of power: theories in subjection. Stanford:

Stanford University Press. 2003 [1990]. Problemas de gênero: feminismo e subversão da identidade. Rio de Janeiro: Civilização Brasileira. 2004. Precarious life: the powers of mourning and violence. London/New York: Verso. 2005. Giving an account of oneself. New York: Fordham University Press. 2007 [1990]. Gender trouble. feminism and the subversion of identity. New York: Routledge.

FRASER, N. 2011. "Entrevista com Nancy Fraser" (concedida a Ingrid Cyfer e Raphael Neves). In: ABREU, Maria A. (org.). Redistribuição, reconhecimento e representação: diálogos sobre igualdade de gênero. Brasília: Ipea. Disponível em: <http://www.ipea.gov.br/portal/images/ stories/PDFs/livros/livros/livro_redistreconhecimento.pdf $>$. Acesso em: 18 mar. 2015.

76 HARDWICK, E. 1953. "The subjection of women". Partisan Review, v. 20, n. 3, pp. 321-31.

KOJĖVE, Alexandre. 2002. Introdução à leitura de Hegel. Rio de Janeiro: Eduerj.

KRISTEVA, J. 1986. "Women's time”. In: MOI, T. (ed.). The Kristeva Reader. London: Blackwell.

KRUKS, S. 1992. "Gender and subjectivity: Simone de Beauvoir and contemporary feminism”. Signs, v. 18, n. 1, pp. 89-110. . 1995. "Simone de Beauvoir: teaching Sartre about freedom." In: SIMONS, M. (ed.). Feminist interpretations of Simone de Beauvoir. Pennsylvania: The Pennsylvania State University Press.

LEVINAS, E. 2011 [1961]. Totality and infinity: an essay on exteriority. Pennsylvania: Duquesne University Press

MERLEAU-PONTY, M. 1999. Fenomenologia da percepção. São Paulo: Martins Fontes.

MOI, T. 1990. Feminist theory $\mathcal{E}$ Simone de Beauvoir. Oxford: Blackwell. 2001 [1999]. What is a woman?: and other essays. Oxford/New York:

Oxford University Press.

PILLARDI, J.-A.1995. "Feminists read The Second Sex". In: SIMONS, M. (ed.). Feminist interpretations of Simone de Beauvoir. Pennsylvania: The 
Pennsylvania State University Press.

SARTRE, J.-P. 2011. O ser e o nada. Petrópolis, RJ: Vozes.

SIMONS, M. 1995. "Introduction”. In: (ed.). Feminist interpretations of Simone de Beauvoir. Pennsylvania: The Pennsylvania State University Press.

TAMBORNINO, J. 1999. "Locating the body: corporeality and politics in Hannah Arendt". The Journal of Political Philosophy, v. 7, n. 2.

WARD, Julie. 1995. "Beauvoir's two senses of 'body' in The second sex." In: SIMONS, M. (ed.). Feminist interpretations of Simone de Beauvoir. Pennsylvania: The Pennsylvania State University Press.

ZERILLI, L. 1995. "The arendtian body". In: HONIG, B. (ed.). Feminist interpretations of Hannah Arendt. Pennsylvania: Pennsylvania State University Press. 


\section{AFINAL, O QUE É UMA MULHER? SIMONE DE BEAUVOIR E "A QUESTÃO DO SUJEITO" NA TEORIA CRÍTICA FEMINISTA}

INGRID CYFER

Resumo: Judith Butler, em sua reflexão sobre o sujeito do feminismo, denuncia as exclusões decorrentes e legitimadas pela "mulher universal". Seyla Benhabib, por sua vez, formula outra concepção de sujeito, a partir do debate com Butler, buscando respostas capazes de preservar o que considera totalmente comprometido no argumento de Butler: a possibilidade de justificar uma concepção normativa de igualdade de gênero e ação política. No entanto, Benhabib não parece ter sido totalmente bem-sucedida nessa formulação, porque o núcleo do self em seu modelo é neutro quanto ao gênero. É em razão desse "déficit de contextualização" em Benhabib que Simone de Beauvoir é introduzida no debate. O principal argumento deste artigo é o de que a concepção de subjetividade que Beauvoir enuncia em $O$ segundo sexo pode complementar a noção de sujeito de Benhabib com uma concepção mais contextualizada e corporificada do self, que seria compatível tanto com a demanda de contextualizar o sujeito quanto com o compromisso teórico e político da crítica feminista com a igualdade de gênero.

Palavras-chave: Feminismo; Concepção de Self; Subjetividade; Judith Butler; Seyla Benhabib; Simone de Beauvoir; Igualdade de Gênero.

\section{AFTER ALL WHAT'S A WOMAN?: SIMONE DE BEAUVOIR AND "THE QUESTION OF THE SUBJECT" IN FEMINIST CRITICAL THEORY}

Abstract: Judith Butler, in her reflection on the subject of feminism, denounced the exclusions that derive from the "universal woman". On the other hand, Seyla Benhabib formulates another conception of the subject in order to find a way of contextualizing the subject while preserving what she considers fully committed in Butler's argument: 
the possibility of justifying a normative conception of gender equality and political agency. However, it seems that Benhabib has not been completely successful in her formulation because the core of the self in her model is neutral regarding gender. In order to try to resolve the "deficit of contextualization" in Benhabib's account of the subject, Simone de Beauvoir's conception on subjectivity is introduced into this debate. The main claim of this article is that the conception of subjectivity that Beauvoir sets in The Second Sex could complement Benhabib's conception of the subject with a more embodied self that would be compatible with both, the demand of contextualizing the subject and the theoretical and political commitments of feminist critique to gender equality.

Keywords: Feminism; Conceptions of the Self; Subjectivity; Seyla Benhabib; Judith Butler; Simone de Beauvoir; Gender Equality.

Recebido: 09/12/2014 Aprovado: 20/02/2015 